\title{
Investigation of Optical Properties of Magnesium Oxide Films Obtained by Spray Pyrolysis Technique
}

\author{
O.V. Diachenko, A.S. Opanasuyk, D.I. Kurbatov \\ Department of Electronics and Computer Technics \\ Sumy State University, SSU \\ Sumy, Ukraine \\ opanasyuk_sumdu@ukr.net
}

\author{
H. Cheong \\ Department of Physics \\ Sogang University \\ Seoul, South Korea
}

\begin{abstract}
Today more and more areas of optoelectronics used oxide materials, as a result, their study, is very important . Therefore, in this paper, we study optical properties of magnesium oxide films.
\end{abstract}

Keywords-films; magnesium oxide, band gap, spray-pyrolysis, optoelectronics, optical properties.

\section{INTRODUCTION}

Magnesium oxide is promising material in semiconductor technology. It is used as a chemically stable buffer layer for growing high-temperature superconductors and ferroelectric materials, as a dielectric layer in plasma screens and microwave devices, as an alternative to $\mathrm{SiO}_{2}$ insulator in high capacity electrical circuits and etc. Due to the high optical transparency in a wide wavelength range, $\mathrm{MgO}$ is a promising candidate for a variety of new applications, such as in lighting industry, optical systems and laser technology, control technology, as well as creation thermal sensors. Furthermore, the compound has been applied as a protective and antireflection layer in photovoltaic solar energy $[1,2]$.

There are various methods for obtaining $\mathrm{MgO}$ films, such as metalorganic molecular beam epitaxy [5], vapor phase epitaxy [3], sol-gel synthesis [4], reactive sputtering [6], pulsed laser deposition [7], chemical vapor deposition [8, 9]. Compare to methods that listed above the spray pyrolysis has a number of advantages. It does not require expensive vacuum equipment and high-quality substrates, it provides high-speed deposition of layers on large area substrates with various precursors.

During deposition process of semiconductor and dielectric films, a nanoparticle of precursor solution is spraying onto a heated substrate surface where the components of the solution under the influence of temperature interact to form chemical compounds. Chemicals are selected so that, in addition to the required compound, the remaining reaction products are volatile at the temperature of film deposition.

\section{GENERAL INFORMATION}

Magnesium oxide thin films were obtained by spray pyrolysis method. For sample preparation, the glass substrates were ultrasonically cleaned with distilled water for 6 minutes. 0.2 molar of magnesium chloride hexahydrate $\left(\mathrm{MgCl}_{2} \cdot 6 \mathrm{H}_{2} \mathrm{O}\right)$ were dissolved in deionized water and used as precursor solution. We used this precursor for the first time for the deposition of $\mathrm{MgO}$ film.

The air flow with a pressure of $0.2 \mathrm{MPa}$ was used to transport dispersed precursor particles onto the heated substrate. The diameter of the nozzle is $0.2 \mathrm{~mm}$. The distance between the nozzle and the heated substrate surface was equal to $15 \mathrm{~cm}$. The substrates temperature during the obtaining of films was measured using a chromel-alumel thermocouple. The substrate temperature range for synthesis of the films was chosen from $\mathrm{T}_{\mathrm{s}}=640 \mathrm{~K}$ to $690 \mathrm{~K}$ with step $\Delta 10 \mathrm{~K}$. The procedure of obtaining oxides films has been described more detailed in [10]

The thickness of the samples was determined using a probe Profilers Dektak XT. In order to increase accuracy, three measurements of each sample were held.

The optical properties (transmittance, absorption and band gap energy) were measured at room temperature of the $\mathrm{MgO}$ films were determined by using $721 \mathrm{G}$ visible spectrophotometer in the wavelength range from 320 to 1000 $\mathrm{nm}$.

\section{RESULTS AND DISCUSSION}

Established that the average thickness of the samples ranged from $0.8 \mu \mathrm{m}$ at $\mathrm{T}_{\mathrm{s}}=640 \mathrm{~K}$ to $2.2 \mu \mathrm{m}$ at $\mathrm{T}_{\mathrm{s}}=690 \mathrm{~K}$ and increases with increasing substrate temperature.

Transmittance spectra of magnesium oxide film, deposited on glass substrate, are presented in Fig. 1. As can see from the figure the transmittance of films obtained at substrate temperature $\mathrm{T}_{\mathrm{s}}=620$ and $630 \mathrm{~K}$ are lower than films deposited at higher temperature $\mathrm{T}_{\mathrm{s}}$.

The absorption spectrum of the film is required to calculate the band gap material $\mathrm{E}_{\mathrm{g}}$. Absorption spectra were determined from the spectral transmittance using the next equation:

$$
\alpha=1 / d \cdot \ln (1 / T)
$$
12]. 


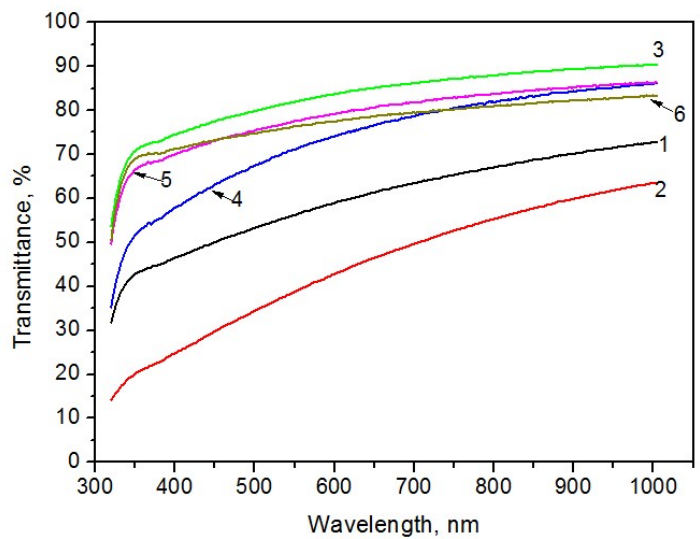

Fig. 1. Transmittance spectra of magnesium oxide film, deposited at substrate temperatures $\mathrm{T}_{\mathrm{s}}=620 \mathrm{~K}(1), 630 \mathrm{~K}(2), 640 \mathrm{~K}(3), 650 \mathrm{~K}(4), 660 \mathrm{~K}$ (5), $670 \mathrm{~K}(6)$

$$
\alpha h v=A(h v-E g)^{n / 2},
$$

where $n$ is a number that depends on the nature of the transition.

In this case, its value was found to be 1 because $\mathrm{MgO}$ is direct gap semiconductor. Figure 2 shows calculated absorbance spectra.

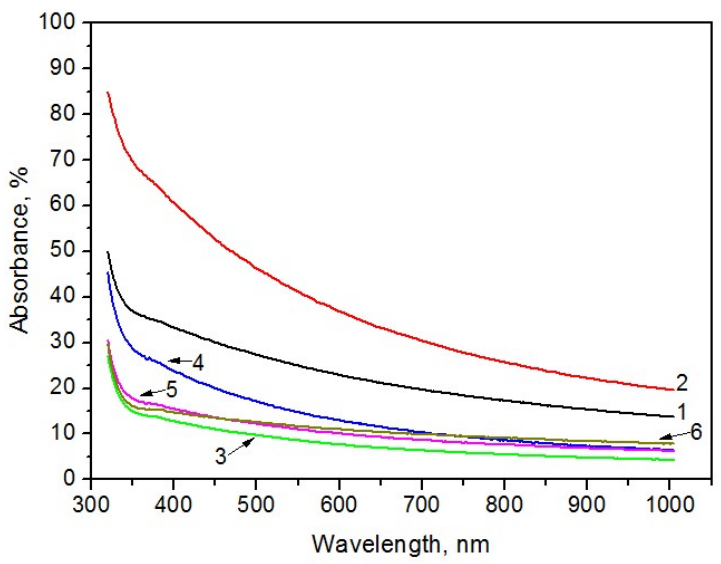

Fig. 2. Absorbance spectra of magnesium oxide film, deposited at substrate temperatures $T_{s}=620 \mathrm{~K}(1), 630 \mathrm{~K}(2), 640 \mathrm{~K}(3), 650 \mathrm{~K}(4), 660 \mathrm{~K}(5), 670$ $\mathrm{K}(6)$.

Figure 3 is a typical Tauc plot, which shows $(\alpha h v)^{2}$ versus $h v$ for the magnesium oxide film obtained at substrate temperature $T_{s}=660 \mathrm{~K}$. The intersection of the straight line with the $h v$-axis determines the optical band gap energy $E_{g}$ [12]. It was found to be about $3.69 \mathrm{eV}$ which is much lower than the bulk band gap of the $\mathrm{MgO}$ crystal. The same values of band gap energy were found for samples obtained at $T_{s}=670$ $690 \mathrm{~K}(E g=3.63-3.69 \mathrm{eV})$. A few fewer values were found for sample deposited at $T_{s}=640 \mathrm{~K}$ and $650 \mathrm{~K}$ were 3.56 and $3.36 \mathrm{eV}$, respectively.

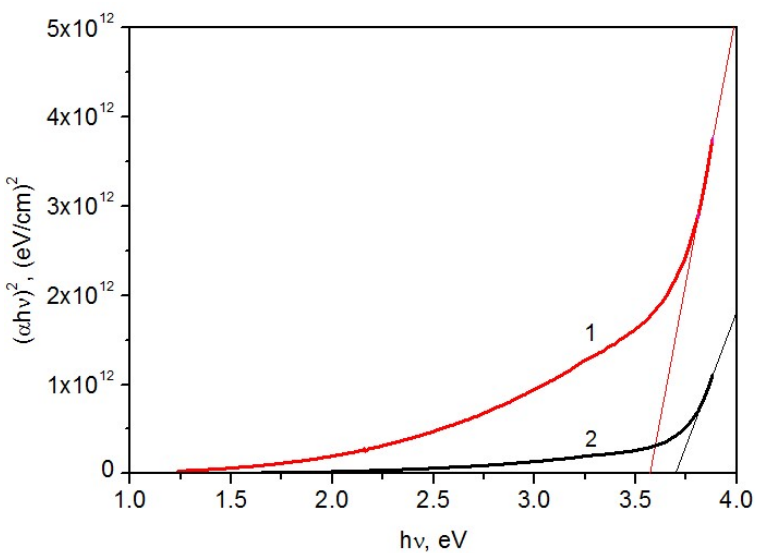

Fig. 3. $E_{g}$ for the magnesium oxide film obtained at substrate temperature $T_{s}$ $=640 \mathrm{~K}(1), 650 \mathrm{~K}(2)$,

\section{ACKNOWLEDGMENT}

This work was supported by the State Fund for Fundamental Research (project №F61/70-2015), by the Ministry of Education and Science of Ukraine (Grant № 0113U000131, 0115U000665c), and by the New \& Renewable Energy of the Korea Institute of Energy Technology Evaluation and Planning (KETEP) grant funded by the Korea government Ministry of Trade, Industry and Energy. (No. 20123010010130).

\section{REFERENCES}

[1] T. Hutzler, A. Krell, "MgO - transparent ceramics with high thermal conductivity”, Fraunhofer IKTS Reports, 2013.

[2] N. M. A. Hadia, H. A. H. Mohamed, "Characteristics and optical properties of $\mathrm{MgO}$ nanowires synthesized by solvothermal method", Materials Science in Semiconductor Processing, vol. 29, pp. 238-244, 2015.

[3] S. S. Lee, "Vapor phase epitaxy of magnesium oxide on silicon using methylmagnesium alkoxides", CVD XV: Proceedings of the Fifteenth International Symposium on Chemical Vapor Deposition, vol. 2000, pp. 277,2000 .

[4] J. G. Yoon, H. K. Kim, "Structural Characterization of Sol-Gel Derived MgO Thin Film on Si Substrate", Journal-Korean Physical Society, vol. 31, pp. 613-616, 1997.

[5] F. Niu, B. H. Hoerman, B. W. Wessels, "Metalorganic Molecular Beam Epitaxy of Magnesium Oxide on Silicon”, MRS Proceedings, vol. 619, pp. 149, 2000.

[6] Y. W. Choi, J. Kim, "Reactive sputtering of magnesium oxide thin film for plasma display panel applications", Thin solid films, vol. 460, pp. 295-299, 2004.

[7] S. Kaneko, "Growth of Nanocubic MgO on Silicon Substrate by Pulsed Laser Deposition", Japanese Journal of Applied Physics, vol. 52, pp. $01 \mathrm{AN} 02,2012$.

[8] J. H. Boo, "Growth of magnesium oxide thin films using single molecular precursors by metal-organic chemical vapor deposition", Thin Solid Films, vol. 341, pp. 63-67, 1999. 
[9] J. M. Zeng, "Preparation and characterization of epitaxial MgO thin film by atmospheric-pressure metalorganic chemical vapor deposition", Journal of crystal growth, vol. 169, pp. 474-479, 1996.

[10] O. Dobrozhan, A. Opanasyuk, H.Cheong, "Influence of substrate temperature on the structural and optical properties of crystalline $\mathrm{ZnO}$ films obtained by pulsed spray pyrolysis", Surface and Interface Analysis, vol.47, pp. 601-606, 2015.

[11] J. W. Chen, D. C. Perng, J. F. Fang, " Nano-structured $\mathrm{Cu}_{2} \mathrm{O}$ solar cells fabricated on sparse $\mathrm{ZnO}$ nanorods", Solar Energy Materials and Solar Cells, vol. 95, pp. 2471-2477, 2011.

[12] V.V. Starikov, M.M.Ivashchenko, A.S. Opanasyuk, "Surface morphology and optical properties of CdSe films obtained by the close spaced sublimation technique", J. Nano Electron. Phys., vol. 1, pp.119$126,2009$. 
Investigation of Optical Properties of Magnesium Oxide Films Obtained by Spray Pyrolysis Technique [Текст] / O.V. Diachenko, A.S. Opanasuyk, D.I. Kurbatov, H. Cheong // 7th International Conference on Advanced optoelectronics and lasers (CAOL), Ukraine, Odessa September 12-15. - Odessa: I. I. Mechnikov National University, 2016. - C. 31-33. 